\title{
UPAYA REDUKSI SEARCHING TIME DENGAN METODE 5S PADA AREA GUDANG PENYIMPANAN BARANG DI PT URF
}

\author{
Sri Wardani ${ }^{1}$, Intan Bunga Kharisma ${ }^{2}$, Yoga R Nurazis ${ }^{3}$ \\ Program Studi Teknik Industri, Fakultas Teknologi Industri \\ Universitas Widyatama \\ Jl. Cikutra No 204 A Bandung \\ sri.wardani@widyatama.ac.id, intan.bunga@widyatama.ac.id, yoga.nurazis@widyatama.ac.id
}

\begin{abstract}
Abstrak
PT URF merupakan perusahaan pengadaan dan jasa yang bergerak di bidang refrigerasi khususnya dibidang konstruksi bangunan terintegrasi pendingin. Dalam melakukan pengadaannya, PT URF memiliki gudang sebagai tempat penyimpanan barang dimana merupakan komponen penting dan berkontribusi penting dalam kecepatan sebuah pekerjaan proyek. Namun saat ini perusahaan masih menggunakan cara konvensional dalam sistem penyimpanan barangnya. Sehingga dala upaya perbaikannya, perusahaan melakukan perancangan perbaikan sistem penataan, pemilahan, pembersihan, dan pemeliharaan barang di area gudang penyimpanan barang menggunakan salah satu tools lean yaitu konsep $5 S$ yang bertujuan agar dapat mereduksi searching time persediaan barang di area gudang penyimpanan. Hasil perancangan yang dilakukan adalam melakukan penataan ulang penempatan barang atau material, melakukan pembersihan, dan menerapkan prosedur sesuai dengan konsep $5 S$.
\end{abstract}

Kata kunci: Lean, 5S, Searching Time, Area Gudang Penyimpanan Barang

\section{Abstract}

PT URF is a procurement and service company engaged in the refrigeration sector, especially in the field of refrigeration integrated building construction. In carrying out its procurement, PT URF has a warehouse as a storage area for goods which is an important component and makes an important contribution to the speed of a project work. However, currently the company still uses conventional methods in its storage system. So that in its repair efforts, the company plans to improve the arrangement, sorting, cleaning and maintenance of goods in the warehouse area using one of the lean tools, namely the $5 S$ concept, which aims to reduce the searching time for inventory in the warehouse area. The results of the design carried out are rearranging the placement of goods or materials, cleaning, and implementing procedures in accordance with the $5 S$ concept.

Keywords: Lean, 5S, Searching Time, Warehouse Storage Area.

\section{Pendahuluan}

Kemajuan teknologi baik di Indonesia maupun global berkembang sangat pesat. Kemajuan tersebut terjadi di berbagai bidang kehidupan yaitu sektor industri, jasa, konstruksi, properti, dan transportasi. Oleh karena itu, persaingan antar perusahaan yang semakin ketat menuntut perusahaan untuk senantiasa melakukan peningkatan efektifitas dan efisiensi kinerja di seluruh aspek perusahaan. Dimana perusahaan harus mengikuti perkembangan iptek dan menerapkan pengendalian maupun pengawasan agar keefektifan dan keefisienan perusahaan mencapai hasil yang maksimal.

PT URF merupakan perusahaan pengadaan barang dan jasa yang bergerak di bidang refrigerasi khususnya dibidang konstruksi bangunan terintegrasi pendingin. Perusahaan ini dibangun bedasarkan pengalaman dan pengetahuan professional dari para pendiri di bidang refrigerasi. PT URF secara khusus menyediakan pengadaan dan jasa konstruksi maupun bangunan terintegrasi pendingin maupun instalasi mesin refrigerasi. PT URF dalam hal ini mendukung dan mengembangkan teknologi cold chain di Indonesia.

Dalam melakukan pengadaannya, PT URF memiliki gudang sebagai tempat penyimpanan barang untuk menunjang kelancaran proyek yang dikerjakan. Area gudang penyimpanan merupakan komponen penting dan berkontribusi penting dalam kecepatan 
sebuah pekerjaan proyek. Namun saat ini perusahaan masih menggunakan cara konvensional dalam sistem penyimpanan barangnya.

Staf gudang bertanggung jawab dalam menjamin area gudang penyimpanan tertata dengan baik, rapi, dan bersih. Tetapi saat ini hal tersebut belum terlaksana secara maksimal membutuhkan waktu yang cukup lama dalam pencarian persediaan barang. Oleh karena itu, perusahaan perlu membantu staf gudang dalam melakukan penerapan konsep $5 S$ karena sangat berpengaruh pada penataan, pemilahan, pembersihan, dan pemeliharaan barang di area tersebut. Perancangan konsep $5 S$ ini bertujuan untuk merancang perbaikan lingkungan kerja menggunakan metode 5S (Seiri, Seiton, Seiso, Seiketsu, dan Shitsuke) agar dapat mereduksi searching time persediaan barang di area gudang penyimpanan.

Menurut Osada (1995) pada bukunya yang berjudul, "The Five Keys to a Total Quality Environmen" mengemukakan bahwa 5S merupakan serangkaian aktivitas pemilahan, penataan, pembersihan, pemeliharaan dan pembiasaan, yang diperlukan untuk melaksanakan pekerjaan dengan baik.

\section{KAJIAN LITERATUR}

\section{II.1.1 KONSEP LEAN}

Lean adalah suatu upaya terus menerus (continuous improvement effort) untuk menghilangkan pemborosan (waste), meningkatkan nilai tambah (value added) produk (barang dan/ jasa) dan memberikan nilai kepada pelanggan (customer value) (Gaspersz, 2008)

\section{II.1.2 KONSEP 5S}

Program 5S (Seiri, Seiton, Seiso, Seiketsu dan Shitsuke) merupakan dasar bagi mentalitas karyawan untuk melakukan perbaikan (improvement) dan juga untuk mewujudkan kesadaran mutu (quality awareness) (Heizer and Render, 2009).

5S sendiri merupakan singkatan dari Seiri (Sort), Seiton (Straighten), Seiso (Shine), Seiketsu (Standardize), dan Shitsuke (Sustain). Dalam bahasa Indonesia diterjemahkan sebagai $5 \mathrm{R}$ yang berarti Ringkas, Rapi, Resik, Rawat, Rajin. Menurut Imai (2001) 5S sangatlah penting karena merupakan pondasi dalam membuat suatu proses menjadi sependek mungkin, mengurangi biaya produksi, output yang berkualitas dan mengurangi timbulnya kecelakaan dengan adanya kondisi yang lebih baik.

\section{Seiri (Ringkas)}

Konsep awal dari 5S adalah seiri yaitu pemilahan barang. Tujuan langkah seiri yaitu untuk memindahkan barang yang tidak digunakan dari area kerja (Agrahari, 2015).

Tindakan yang diambil dari langkah ini yaitu dengan membedakan barang yang sudah tidak digunakan lagi untuk tidak memenuhi area kerja hand add. Sedangkan pemisahan barang yang sering digunakan dengan yang jarang digunakan berdasarkan dari frekuensi penggunaan barang tersebut. Barang barang tersebut akan disimpan akan ditentukan tempat penyimpanannya menurut frekuensi penggu-naannya. Penempatan tersebut akan diatur sebagai berikut.

Tabel 1. Kriteria Penyimpanan Barang

\begin{tabular}{ll}
\hline \multicolumn{1}{c}{ Frekuensi } & \\
Penggunaan Barang & \multicolumn{1}{c}{ Tempat Penyimpanan } \\
\hline Tinggi & Dekat Operator \\
Rata-rata & Tengah Area Kerja \\
Rendah & Gudang \\
\hline
\end{tabular}

Pengelompokkan barang yang memiliki frekuensi yang tinggi akan diletakkan di dekat operator. Tujuan peletakkan barang tersebut di dekat operator yaitu untuk memudahkan operator saat akan menggunakannya.

\section{Seiton (Rapi)}

Konsep kedua dari metode $5 \mathrm{~S}$ adalah seiton yaitu rapi. Tujuan dari seiton yaitu dengan melakukan penyimpanan fungsional barang tersebut untuk memudahkan operator saat mencari dan mengembalikannya. Barang yang akan disimpan tersebut harus mempunyai lokasi penyimpanan barang yang tetap dan jelas. Metode penyimpanan yang dika-takan baik apabila setiap orang dapat melihat, mencari dan mengembalikannya barang dengan mudah dan jelas (Yosi \& Nyoman, 2018). Berikut beberapa langkah sebelum melakukan seiton sebagai berikut.

1. Menentukan lokasi penyimpanan barang yang tepat. Hal ini dilakukan untuk mengurangi waktu yang diperlukan untuk menyimpan dan mengambil barang. Menunggu dalam segala hal merupakan hal yang tidak bernilai yang berarti berhenti saat bekerja (Fabrizio \& Tapping, 2006). 
2. Memberikan garis batas pada lokasi barang Setiap barang yang akan diletakkan di satu lokasi akan diberi tanda batas untuk mengetahui lokasi penyimpanan barang tersebut (Sharma \& Singh, 2015). Bila barang tersebut keluar dari tanda batas tersebut dapat dinyatakan bahwa kondisi area tersebut kurang rapi.

\section{Seiso (Resik)}

Konsep ketiga dari metode $5 \mathrm{~S}$ adalah seiso yaitu resik. Tujuan dari seiso yaitu menjaga kebersihan lingkungan kerja, material dan alat bantu produksi. Kebersihan merupakan tanggung jawab setiap pekerja. Lingkungan kerja yang bersih juga memberikan nilai tambah bagi perusahaan untuk menjamin kualitas produk yang dihasilkan. Berikut merupakan penerapan yang dapat dilakukan di area kerja sebagai berikut.

1. Menyediakan sarana kebersihan dalam jumlah yang cukup dan memadai. Sarana kebersihan harus tersedia dalam jumlah yang cukup dan memadai untuk mewujudkan area kerja yang bersih. Peralatan kebersihan dalam jumlah yang cukup dan memadai maka kegiatan kebersihan dapat dilakukan dengan baik.

2. Melaksanakan kegiatan kebersihan secara periodic. Kegiatan kebersihan secara periodik diharapkan setiap tenaga kerja memiliki rasa tanggung jawab untuk merawat dan selalu menjaga kebersihan area kerja tersebut.

\section{Seiketsu (Rawat)}

Konsep keempat dari metode $5 \mathrm{~S}$ adalah seiketsu yaitu rawat. Tujuan dari seiketsu memelihara kondisi area kerja yang bersih dan rapi dengan mengikuti langkah 3S sebelumnya. Langkah rawat yang dimaksudkan yaitu untuk terus menjalankan pelaksanaan disiplin 3S supaya dapat berjalan dengan baik. Sasaran yang dituju dalam langkah rawat ini adalah menjaga area kerja tersebut pada kondisi ringkas, rapi dan bersih. Berikut merupakan penerapan yang dapat dilakukan di area kerja sebagai berikut.

1. Melakukan inspeksi terhadap pelaksanaan 5S. Pelaksanaan program 5S tersebut dapat berjalan dengan baik apabila selalu dilakukan oleh setiap operator hand add sendiri. Program inspeksi tersebut dilakukan dengan cara datang langsung melihat ke area hand add lalu melakukan penilaian dan menunjukan secara langsung masalah yang perlu diselesaikan. Program selain inspeksi yaitu dengan melakukan evaluasi secara langsung dengan operator hand add untuk mengetahui masukan yang dapat dilakukan perbaikan.

2. Melaksanakan kegiatan kebersihan secara periodik Kegiatan kebersihan secara periodik diharapkan setiap tenaga kerja memiliki rasa tanggung jawab untuk merawat dan selalu menjaga kebersihan area kerja tersebut.

\section{Shitsuke (Rajin)}

Konsep terakhir dari metode $5 \mathrm{~S}$ adalah shitsuke yaitu rajin. Langkah shitsuke ini bertujuan untuk melakukan pekerjaan dengan benar sesuai dengan prosedur yang berlaku. Tujuan utama dari shitsuke untuk menanamkan budaya $5 \mathrm{~S}$ sebagai pola pikir untuk menciptakan kondisi area kerja yang lebih baik (Ishijima et al., 2015). Langkah - langkah penerapan di area kerja dalam tahapan shitsuke yaitu sebagai berikut.

1. Melakukan kegiatan 5S Sukses. Kegiatan 5S Sukses ini bertujuan untuk tetap menjalankan program 5S tetap berjalan terus menerus. Pelaksanaan kegiatan ini akan dilakukan dengan membutuhkan waktu sekitar 5 menit sebelum mengakhiri shift kerja tiap harinya. Tujuan dari kegiatan 5S Sukses ini untuk membuat budaya kerja dalam aktivitas sehari-hari.

2. Melakukan pekerjaan sesuai dengan prosedur. Setiap operator harus melakukan tugas dan tanggung jawab sesuai dengan prosedur yang telah ditentukan. Tujuan melakukan pekerjaan sesuai prosedur supaya pekerjaan yang dilakukan dapat lebih baik dan teratur. Prosedur kerja harus dibuat dengan jelas dan lengkap.

3. Melakukan sistem scoring. Sistem scoring merupakan salah satu cara untuk tetap menjaga eksistensi program 5S di area kerja hand add. Sistem tersebut nantinya akan digunakan pada setiap team di area kerja hand add.

\section{ANALISIS DAN PERANCANGAN}

\section{III.1 Metodologi Penelitian}

Sumber atau pengumpulan data diambil dari hasil observasi, wawancara, dan dokumentasi di PT URF. Kemudian membandingkan data tersebut dengan literatur yang ada. Selanjutnya data tersebut diseleksi berdasarkan kriteria kepentingannya untuk 
mengetahui cara pemeriksaan persediaan barang di gudang. Hal ini dapat disimpulkan sebagai berikut:

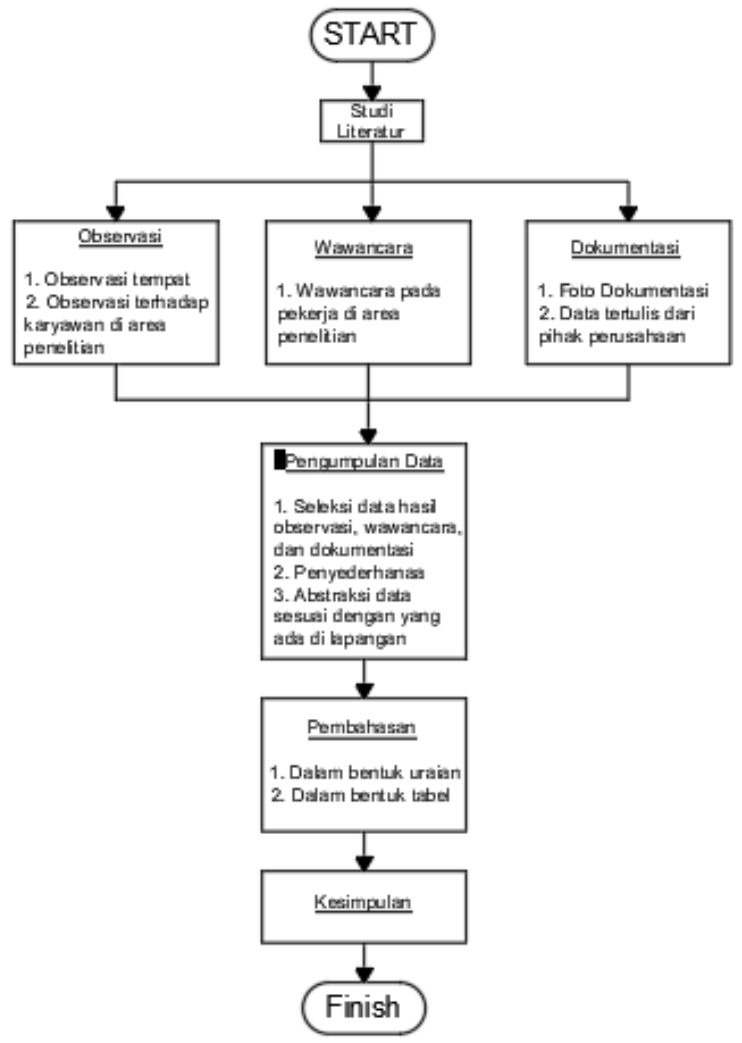

Tabel 1. Diagram Metodologi Penelitian

Data yang diambil merupakan variabel bebas dan terikat dimana variabel bebas sebagai input dimana melakukan upaya perbaikan di area gudang penyimpanan barang dengan menggunakan pendekatan 5S. Sedangkan varibel terikat dalam penelitian adalah sebagai output yang mana untuk melakukan rencana efisiensi terhadap waktu pencarian barang di gudang

\section{III.2 Pembahasan}

Rencana upaya perbaikan dengan melakukan pnerapan konsep $5 S$ digunakan oleh PT URF pada area gudang penyimpanan barang bertujuan untuk melakukan reduksi searching time atau waktu pencarian bagi persediaan barang di area gudang penyimpanan oleh staf gudang sehingga waktu pengerjaan sebuah proyek menjadi lebih efisien. Terdapat data yang telah dikumpulkan yaitu daftar barang yang berada di area gudang penyimpanan, hasil wawancara dengan staf gudang mengenai penataan barang di area tersebut dan hasil dokumentasi di area gudang yang terdapat pada Gambar 1 berikut:

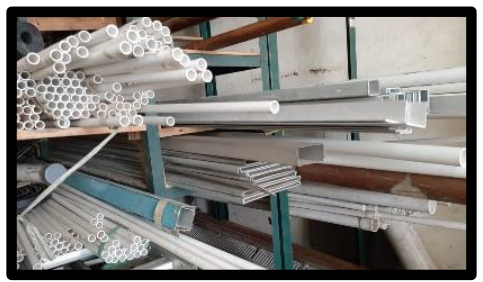

Gambar 1. Penyimpanan Barang di Area Gudang Penyimpanan PT URF

Hasil penelitian menunjukkan bahwa kondisi tata letak barang pada area gudang penyimpanan barang masih jauh dari kata rapi sehingga membuat searching time menjadi lebih panjang dan menyebabkan keterlambatan pemesanan barang yang tidak tersedia. Dalam proses pencarian persediaan barang, berdasarkan pengamatan yang dilakukan seorang staf gudang memiliki waktu yang variatif dengan rentang 2-10 menit untuk setiap barangnya tergantung pada jenis barang yang dicari. Hal ini karena pengaturan penataan barang yang bercampur antara satu material dengan material lain. Sehingga apabila melakukan pencarian persediaan barang untuk sebuah proyek membutuhkan waktu hingga 1 hari kerja dikarenakan daftar barang yang cukup banyak.

Selain itu, dalam melakukan pengepakan atau packing barang, staf gudang melakukannya di area jalan di gudang sehingga terkadang menghalangi akses keluar masuk gudang. Kemudian juga terdapat sampah dan kotoran akibat packing dan handling yang tidak langsung dibersihkan sehingga membuat lingkungan kerja tidak nyaman.

Menurut Imai (2001) $5 S$ sangatlah penting karena merupakan pondasi dalam membuat suatu proses menjadi sependek mungkin, mengurangi biaya produksi, output yang berkualitas dan mengurangi timbulnya kecelakaan dengan adanya kondisi yang lebih baik. Sehingga dalam melakukan upaya perbaikan yaitu melakukan reduksi searching time pada barang di area gudang penyimpanan, pertamatama dilakukan pengelompokkan masalah yang terjadi sebelum area gudang penyimpanan di PT URF belum menerapkan konsep $5 S$ dimana, pengelompokkan masalah berdasarkan konsep $5 S$ adalah sebagai berikut: 


\begin{tabular}{|c|l|}
\hline \multicolumn{2}{|c|}{ Pengelompokkan Masalah dengan Konsep 5S } \\
\hline \multirow{5}{*}{ Seiri } & $\begin{array}{l}\text { Barang dengan jenis dan ukuran yang } \\
\text { berbeda masih bercampur di dalam }\end{array}$ \\
\cline { 2 - 3 } & $\begin{array}{l}\text { Tidak ada ruang khusus untuk packing } \\
\text { barang }\end{array}$ \\
\cline { 2 - 3 } & $\begin{array}{l}\text { Penempatan barang yang menghalangi } \\
\text { jalan staf gudang }\end{array}$ \\
\hline \multirow{5}{*}{ Seiton } & $\begin{array}{l}\text { Tidak adanya pengelompokkan baik } \\
\text { berdasarkan ukuran maupun jenis barang }\end{array}$ \\
\cline { 2 - 3 } & $\begin{array}{l}\text { Terdapat rak dan loker penyimpanan } \\
\text { namun penyimpanannya tidak disusun }\end{array}$ \\
\hline Terdapat material yang disimpan didalam \\
\hline \multirow{5}{*}{ Seiso } & $\begin{array}{l}\text { Satu jenis barang dapat disimpan di } \\
\text { beberapa tempat }\end{array}$ \\
\hline \multirow{5}{*}{ Seiketsu } & $\begin{array}{l}\text { Sampah yang terjadi saat proses } \\
\text { packing tidak dibuang dengan } \\
\text { semestinya sehingga membuat lingkungan }\end{array}$ \\
\hline \multirow{2}{*}{$\begin{array}{l}\text { Kotoran yang terjadi setelah proses } \\
\text { handling tidak langsung dibersihkan }\end{array}$} \\
\hline $\begin{array}{l}\text { Kesadaran para pekerja dalam } \\
\text { menerapkan seiri, seiton, \& seiso masih } \\
\text { kurang karena tidak adanya peraturan }\end{array}$ \\
\hline $\begin{array}{l}\text { Belum adanya penanggulangan terhadap } \\
\text { kesadaran para pekerja mengenai } \\
\text { pentingnya kerapian dan kebersihan kerja }\end{array}$ \\
\hline
\end{tabular}

Tabel 2. Pengelompokkan Masalah dengan Konsep $5 S$

Berdasarkan hasil pengelompokkan masalah dengan Konsep 5S. Rancangan upaya perbaikan dengan konsep $5 \mathrm{~S}$ area gudang penyimpanan barang PT URF meliputi perancangan seiri, seiton, seiso, seiketsu dan shitsuke dapat membantu menemukan solusi yang paling efektif dalam mereduksi searching time barang di area gudang penyimpanan. Dimana, rancangan upaya perbaikan searching time barang dengan konsep $5 S$ adalah sebagai berikut:

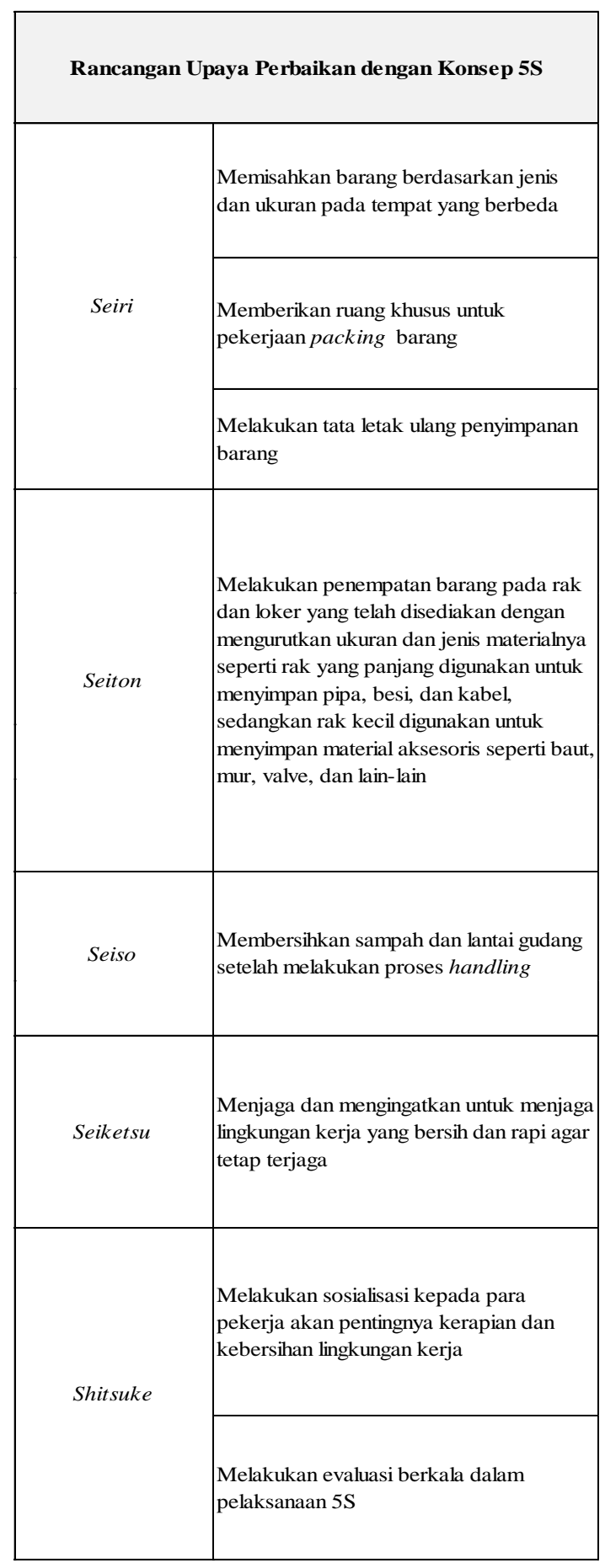

Tabel 3. Rancangan Upaya Perbaikan dengan Konsep $5 S$

Hasil perancangan upaya reduksi searching time dengan konsep 5S didapatkan bahwa dengan

Sri Wardani, Intan Bunga Kharisma, Yoga Nurazis 
menerapkan seiri dan seiton akan dapat membantu mengurangi searching time barang di area penyimpanan. Hal ini karena penataan dan pengelompokkan barang baik berdasarkan jenis maupun ukuran barang di gudang sangat menentukan kecepatan pencarian barang. Selain itu, dengan adanya perancangan seiso, maka kondisi area gudang penyimpanan menjadi lebih bersih dan nyaman untuk digunakan sehingga pekerja akan bekerja lebih produktif. Perancangan seiketsu dan shitsuke juga dapat membantu pereduksian waktu pencarian barang apabila perusahaan bekerjasama dengan staf gudang dalam menerapkan prosedur dan melakukan checklist rutin sebagai pengawasan dalam menjaga kondisi di area gudang penyimpanan.

\section{KESIMPULAN DAN SARAN}

Kondisi penataan barang dan penggunaan area gudang penyimpanan di PT URF masih dapat dikatakan belum terkontrol. Sehingga sulitnya proses pencarian barang di gudang menyebabkan proses pengadaan barang dan pekerjaan proyek menjadi tidak efektif. Hasil penelitian menunjukkan bahwa apabila PT URF menerapkan konsep $5 S$ untuk area gudang penyimpanan dapat sangat membantu dalam mereduksi waktu pencarian barang (searching time) karena dengan menerapkan konsep seiri dan seiton barang di gudang dapat ditata ulang dengan mengatur penyimpanan sesuai dengan jenis dan ukuran barang, selain itu melakukan pemaksimalan rak dan loker yang ada di gudang dalam menunjang penyimpanannya. Selain itu, konsep seiso jika diterapkan akan membuat pekerja lebih nyaman karena area kerja yang bersih. Kemudian seiketsu membantu dalam melakukan penerapan prosedur penyimpanan dan proses pencarian barang yang kemudian dengan menerapkan konsep shitsuke dalam melakukan pengawasan dan penjagaan kondisi area gudang penyimpanan dengan cara melakukan checklist rutin seperti melakukan pemeriksaan penempatan barang maupun kebersihan area gudang penyimpanan.

\section{REFERENSI}

Kurniawan, Y., \& Sutapa, I. N. (2018). Perancangan dan Penerapan 5S di Area Hand Add PT Charoen Pokphand Indonesia Feedmill Balaraja. Jurnal Titra, 6(2), 167-174.

Farihah, T., \& Krisdiyanto, D. (2018). Penerapan 5S (Seiri, Seiso, Seiton, Sheiketsu, Shitsuke) pada UKM Olahan Makanan di Dusun Sempu, Desa Wonokerto. Jurnal Bakti Saintek: Jurnal Pengabdian Masyarakat Bidang Sains dan Teknologi, 2(2), 43-49.

Osada, Takashi. 1995. The 5S's: Five Keys to a Total Quality Environment. Jakarta: P.T Pustaka Binaman Pressindo.

Imai, M. 2001. Kaizen: Kunci Sukses Jepang dalam Persaingan. Penerbit PPM, Jakarta.

Sri Wardani, Intan Bunga Kharisma, Yoga Nurazis 